\title{
PENGARUH MOTIVASI BELAJAR TERHADAP HASIL BELAJAR MATEMATIKA SISWA KELAS X DALAM PENERAPAN MODEL PEMBELAJARAN ARIAS (Assurance, Relevance, Interest, Assessment, dan Satisfaction)
}

\author{
Kiki Nia Sania Effendi \\ Universitas Singaperbangsa Karawang \\ qqeffendi@gmail.com
}

\begin{abstract}
ABSTRAK
Penelitian ini bertujuan untuk mengetahui apakah terdapat pengaruh motivasi belajar terhadap hasil belajar siswa dalam penerapan model pembelajaran ARIAS (Assurance, Relevance, Interest, Assessment, dan Satisfaction). Penelitian ini merupakan penelitian eksperimen. Populasi dalam penelitian ini adalah seluruh kelas X SMK Negeri 1 Karawang dengan sampel sebanyak satu kelas. Instrumen penelitian terdiri dari tes, dan angket. Tes yang digunakan adalah tes tipe pilihan ganda beralasan dan uraian. Angket berupa skala motivasi menggunakan Skala Likert. Temuan penelitian ini menunjukkan: terdapat pengaruh motivasi belajar terhadap hasil belajar siswa dalam penerapan model pembelajaran ARIAS (Assurance, Relevance, Interest, Assessment, dan Satisfaction).
\end{abstract}

Kata Kunci: ARIAS (Assurance, Relevance, Interest, Assessment, dan Satisfaction), motivasi belajar, hasil belajar.

\begin{abstract}
This study aims to determine whether there is influence of learning motivation on student learning outcomes in the application of ARIAS learning model (Assurance, Relevance, Interest, Assessment, and Satisfaction). This study was an experimental study. population in this research is class X SMK Negeri 1 Karawang with sample one class. The research instrument consisted of tests, and questionnaires. The tests used are multiple choice type tests that are grounded and descriptions. Questionnaire with Likert scale. The findings of this study show: the influence of learning motivation, relevance, interest, assessment, and satisfaction.
\end{abstract}

Keywords: ARIAS (Assurance, Relevance, Interest, Assessment, and Satisfaction), learning motivation, learning outcomes.

\section{PENDAHULUAN}

Menurut Mcleland dalam (Fatchurrohman, 2011: 63) motivasi berprestasi adalah sebagai suatu usaha untuk mencapai hasil yang sebaik-baiknya dengan berpedoman pada suatu standar keunggulan tertentu (standard of exellence). Ada tiga hal yang melatar belakangi motivasi seseorang menurut Mcleland dalam (Fatchurrohman, 2011 : 64), The Need for Achievement (n-ach) (Kebutuhan akan Prestasi / Pencapaian), The Need for Authority and Power (n-pow) (Kebutuhan akan Kekuasaan), The Need for Affiliation (n- 
affil) (Kebutuhan akan Afiliasi / Keanggotaan) . Adapun indikator motivasi belajar menurut Abin Syamsyudin dalam (Hamdu dan Agustina, 2011 : 92), yaitu : (1) Durasi belajar, (2) Frekuensi belajar, (3) Presistensi dalam belajar, (4) Ketabahan, keuletan dan kemampuannya dalam menghadapi kegiatan dan kesulitan untuk mencapai tujuan, (5) Pengabdian dan pengorbanan untuk mencapai tujuan, (6) Tingkatan aspirasi siswa dalam belajar, (7) Tingkat kualifikasi prestasi belajar, (8) Arah sikapnya terhadap sasaran kegiatan. Dari ketidaksejalanan antara fenomena dan teori yang ada tentang motivasi terlihat bahwa motivasi siswa rendah. Siswa memiliki motivasi yang rendah dalam pembelajaran matematika (Maizon, 2010). Hal tersebut sesuai dengan pengamatan dilapangan yang menunjukan pada umumnya durasi dan frekuensi siswa untuk belajar matematika sedikit, siswa takut gagal dalam mengerjakan tugas sehingga malas mengerjakan tugas dalam mata pelajaran matematika yang diberikan oleh gurunya. Hal ini dikarenakan ketika siswa merasa kesulitan dalam menyelesaikan tugas tersebut sehingga dapat dikatakan minat siswa kurang dalam menyelesaikan masalah pada tugas matematika. Akibatnya untuk menyelesaikan tugas tersebut siswa menyalin pekerjaan milik temannya.

Masalah klasik yang terjadi disekolah yang berkaitan dengan pembelajaran matematika yaitu hasil belajar siswa yang rendah terlihat dari hasil ulang harian dengan nilai rata-rata dibawah KKM. Padahal matematika merupakan salah satu mata pelajaran yang dipelajari siswa di jenjang pendidikan formal mulai dari tingkat SD sampai pada SMA/SMK bahkan pada perguruan tinggi. Hasil belajar adalah pernyataan tentang peserta didik yang meliputi pengetahuan, dan pemahaman sebagai akhir dari pengalaman belajar (Adam, 2002). Menurut Fyan dan maehr (dalam Suprijono, 2010 : 162 ) ada tiga faktor yang mempengaruhi prestasi belajar siswa, yaitu keluarga, sekolah, dan motivasi. Biasanya apabila ada masalah dalam keluarga, belum siap untuk belajar, dan motivasinya belajarnya kurang maka akan mempengaruhi hasil belajarnya. Secara garis besar faktor yang mempengaruhi hasil belajar dibagi menjadi faktor internal yaitu semua faktor yang berada di dalam diri siswa (seperti motivasi, bakat, kesiapan belajar) dan faktor eksternal yaitu semua faktor yang berada di luar diri siswa (misalnya guru). Caroll mengatakan bahwa lima faktor yang mempengaruhi hasil belajar siswa, yaitu bakat siswa, waktu yang tersedia bagi siswa, waktu yang diperlukan guru untuk menjelaskan materi, kualitas pengajaran, dan kemampuan siswa (Sudjana, 2009). Motivasi tidak hanya menjadikan siswa terlibat dalam kegiatan akademik, motivasi juga penting dalam menentukan seberapa jauh siswa akan belajar dari suatu kegiatan pembelajaran atau seberapa jauh menyerap informasi yang 
disajikan kepada mereka. motivasi belajar memiliki peran penting, diantaranya dalam menentukan hal-hal yang dapat dijadikan penguat belajar, memperjelas tujuan belajar yang hendak dicapai, menentukan ragam kendali terhadap rangsangan belajar dan menentukan ketekunan belajar (Uno, 2006). Siswa yang termotivasi untuk belajar sesuatu akan menggunakan proses kognitif yang lebih tinggi dalam mempelajari materi itu, sehingga siswa itu akan meyerap dan memahami materi itu dengan lebih baik. Ruseffendi (2006:8) mengemukakan bahwa siswa sebagai individu yang potensial tidak dapat berkembang banyak tanpa bantuan guru.

Hasil belajar matematika peserta didik yang diajar dengan model pembelajaran ARIAS rata-rata nilai yang didapatkan peserta didik yaitu 76,90 , hal ini menunjukkan bahwa rata-rata hasil belajar peserta didik berada pada kategori tinggi (Lestari, Nursalam, dan Mardhiah, 2017 : 122). Model pembelajaran ARIAS terdiri dari lima komponen yaitu: Assurance (Percaya diri), Relevance (Sesuai dengan kehidupan siswa), Interest (Minat dan Perhatian siswa), Assessment (Evaluasi), Satisfaction (Penguatan) (Rahman dan Amir, 2014). Kelima komponen tersebut merupakan satu kesatuan yang diperlukan dalam kegiatan pembelajaran.

Kompenen pertama yaitu assurance berhubungan dengan sikap percaya diri, relevance berhubungan dengan kehidupan siswa baik berupa pengalaman sekarang atau yang telah dimiliki atau yang akan datang. Selanjutnya interest berhubungan dengan minat atau perhatian siswa, assessment merupakan penilaian yang dilakukan selama proses pembelajaran berlangsung, dan satisfaction berhubungan dengan rasa bangga, puas atau hasil yang dicapai. Model pembelajaran ini adalah hasil dimodifikasi dari model pembelajaran ARCS. Model ARCS (Attention, Relevance, Confidence, Satisfaction), dikembangkan oleh John M. Keller dan Kopp pada tahun 1987, dengan menambahkan komponen assessment pada keempat komponen model pembelajaran tersebut. Model ARCS ini dikenal secara luas sebagai Keller's ARCS Model Of Motivation. Model pembelajaran ini dikembangkan berdasarkan teori nilai harapan (expectancy value theory) yang mengandung dua komponen yaitu nilai (value) dari tujuan yang akan dicapai dan harapan (expectancy) agar berhasil mencapai tujuan itu (Nasih dan Kholidah, 2009: 122). Dengan demikian peneliti ingin mengetahui apakah motivasi belajar siswa dapat mempengaruhi hasil belajar siswa dengan diterapkannya Model pembelajaran ARIAS (Assurance, Relevance, Interest, Assessment, dan Satisfaction). 


\section{METODE PENELITIAN}

Pendekatan dalam penelitian ini yaitu kuantitatif dengan metode pre-eksperimen dengan desain pre-test post-test one group design. Populasi dalam penelitian ini adalah seluruh siswa kelas X SMKN 1 Karawang dengan satu kelas yang dijadikan sampel penelitian yaitu kelas X RPL3. Instrument yang digunakan terlebih dahulu divalidasi dan hasil data yang telah diperoleh dianalisis menggunakan bantuan software SPSS versi 20.0 for Windows. Adapun analisis yang digunakan yaitu regresi linear sederhana serta analisis statistik lain yang relevan.

\section{HASIL DAN PEMBAHASAN}

Proses kegiatan pembelajaran memiliki peranan penting untuk menentukan hasil belajar siswa, karena proses kegiatan ini merupakan proses yang harus rancang sedemikian untuk menghasilkan hasil belajar yang sesuai dengan tujuan pembelajaran yang telah ditetapkan. Dalam rancanganya, seorang guru harus mempertimbangkan motivasi belajar siswa sebagai salah satu faktor yang berperan dalam penentuan hasil belajar siswa. Selama proses pembelajaran pada saat penelitian terlihat siswa termotivasi untuk belajar matematika. Siswa merasa termotivasi dengan adanya penerapan model pembelajaran ARIAS. Hal ini terlihat dari durasi belajar siswa yang lebih lama, frekuensi belajar siswa yang lebih banyak, presistensi dalam belajar, ketabahan, keuletan dan kemampuannya dalam menghadapi kegiatan dan kesulitan untuk mencapai tujuan, pengabdian dan pengorbanan untuk mencapai tujuan, tingkatan aspirasi siswa dalam belajar, tingkat kualifikasi prestasi belajar, arah sikapnya terhadap sasaran kegiatan. Dengan model ini siswa merasa termotivasi karena adanya reward dari guru pada siswa yang mampu memahami materi yang disampaikan olehh guru dengan menerangkan hasil latihan di depan kelas. Ada siswa yang berpendapat bahwa sebelum penerapan model pembelajan ARIAS siswa tersebut kurang termotivasi untuk belajar matematika.

Berdasarkan wawancara dengan guru, motivasi siswa meningkat ketika menggunakan model pembelajaran ARIAS karena lebih banyak siswa yang antusisas menunjukan hasil latihannya di depan kelas dan terlihat siswa-siswa tersebut mampu memahami materi yang sedang dipelajari. Selama kegiatan observasi siswa menunjukan siswa termotivasi untuk belajar matematika. Hal ini terlihat dari siswa-siswa yang menyampaikan pendapat, pertanyaan, dan mempersentasikan tentang materi dan latihan soal materi yang sedang dipelajari secara bergantian dari setiap pertemuannya. Motivasi 
memiliki peranan penting dalam proses pembelajaran. Menurut Pebrinovita (2013: 4) Motivasi belajar merupakan faktor psikis yang berperan penting dalam hal penumbuhan gairah, rasa senang, dan bersemangat siswa dalam belajar. Pada penelitian ini tes dilakukan sebanyak dua kali yaitu pretes dan postes adapun hasilnya pada Tabel 1 .

\begin{tabular}{cccccc}
\multicolumn{7}{c}{ Tabel 1. Hasil Belajar Siswa } \\
\hline Tes & $\mathrm{N}$ & $\begin{array}{c}\text { Nilai } \\
\text { Maksimum }\end{array}$ & $\begin{array}{c}\text { Nilai } \\
\text { Minimum }\end{array}$ & $\begin{array}{c}\text { Rata- } \\
\text { rata }\end{array}$ & $\begin{array}{c}\text { Simpangan } \\
\text { Baku }\end{array}$ \\
\hline Pretes & 33 & 60 & 25 & 42 & 8,75 \\
Postes & 33 & 94 & 53 & 72 & 9,03 \\
\hline
\end{tabular}

Berdasarkan Tabel 1 menunjukan hasil belajar siswa mengalami peningkatan terlihat dari nilai rata-rata pada pretes sebesar 42 dan postes 72 yang artinya ada peningkatan nilai rata-rata sebesar 30. Data yang diperoleh dari skala motivasi merupakan data ordinal, sehingga data ini terlebih dahulu dikonversi menjadi data interval dengan menggunakan MSI. Method of Successive Interval (MSI), yaitu suatu metode untuk mentransformasikan dari skala ordinal menjadi data berskala interval. Setelah data skala motivasi dan tes diperoleh maka dilakuakan analisis regresi linear sederhana. Tujuannya untuk mengetahui apakah motivasi belajar mempengaruhi secara signifikan atau tidak terhadap hasil belajar siswa. Pengolahan data melalui program SPSS versi 20.0 for Windows. Tampilan outputnya seperti terdapat pada Tabel 2.

Tabel 2. Output uji pengaruh motivasi belajar terhadap hasil belajar

\begin{tabular}{|c|c|c|c|c|c|c|}
\hline \multirow[t]{2}{*}{ Model } & & \multicolumn{2}{|c|}{$\begin{array}{l}\text { Unstandardized } \\
\text { Coefficients }\end{array}$} & \multirow{2}{*}{$\begin{array}{l}\text { Standardized } \\
\text { Coefficients } \\
\text { Beta }\end{array}$} & \multirow[t]{2}{*}{$\mathrm{T}$} & \multirow[t]{2}{*}{ Sig. } \\
\hline & & B & Std. Error & & & \\
\hline 1 & (Constant) & -101.239 & 9.879 & & -10.248 & .000 \\
\hline & Motivasi & 1.067 & .061 & .953 & 17.567 & .000 \\
\hline
\end{tabular}

Berdasarkan Tabel 2 diatas persamaan regresi $Y^{\prime}=-101,239+1,067 X$. Artinya, jika motivasi belajar siswa 0 maka hasil belajar siswa bernilai negatif yaitu $-101,239$. Nilai koefisisen regresi variable motivasi bernilai positif yaitu 1,067 yang artinya setiap peningkatan motivasi belajar siswa sebesar 1 maka hasil belajar siswa meningkat sebesar 1,067. Selanjutnya, t hitung sebesar 17,567 dengan signifikansi 0,000. Oleh karena signifikansi $<0,05$, maka $\mathrm{H}_{0}$ ditolak atau terdapat pengaruh secara signifikan motivasi belajar terhadap hasil belajar siswa ditinjau dari kompetensi guru dalam penerapan model pembelajaran ARIAS (Assurance, Relevance, Interest, Assessment, dan Satisfaction).

Pada Tabel 2, terlihat $t_{\text {hitung }}$ sebesar 17,567, dan $t_{\text {tabel }}$ dari tabel statistik pada signifikansi 0,05/2 =0,025 dengan derajat kebebasan df $=\mathrm{n}-2$ atau 33-2 $=31$ yaitu 2,040. Ternyata $-\mathrm{t}_{\text {hitung }}<-\mathrm{t}_{\text {tabel }}$ atau $\mathrm{t}_{\text {hitung }}>\mathrm{t}_{\text {tabel }}=-17,567<-2,040$ atau 17,567 $>2,040$ maka $\mathrm{H}_{0}$ 
ditolak sehingga dapat disimpulkan bahwa terdapat pengaruh secara signifikan motivasi belajar terhadap hasil belajar siswa. Persentase pengaruh motivasi belajar terhadap hasil belajar siswa dalam penerapan model pembelajaran ARIAS (Assurance, Relevance, Interest, Assessment, dan Satisfaction) sebesar 90,9\% yang ditunjukan oleh hasil pengolahan data pada nilai $R$ square sebesar 0,909 di Tabel 3.

Tabel 3. Output Model Summary

\begin{tabular}{cllll}
\hline Model & $\mathrm{R}$ & R Square & Adjusted R Square & $\begin{array}{l}\text { Std. Error of the } \\
\text { Estimate }\end{array}$ \\
\hline 1 & $.953^{\mathrm{a}}$ & .909 & .906 & 2.771 \\
\hline
\end{tabular}

Tabel 3 menunjukan motivasi belajar memiliki pengaruh yang besar pada hasil belajar siswa dalam penerapan model pembelajaran ARIAS (Assurance, Relevance, Interest, Assessment, dan Satisfaction). Dalam hal ini, dapat dikatakan guru berhasil dalam mengiplementasikan model pembelajaran ARIAS (Assurance, Relevance, Interest, Assessment, dan Satisfaction). Faktor yang mempengaruhi motivasi belajar siswa antara lain adalah peran guru yang profesional didalam kelas yang dapat mempengaruhi semangat belajar seorang siswa (Syah, 2007: 151). Guru yang profesional mampu memotivasi siswanya untuk belajar lebih giat lagi untuk mencapai prestasi yang diharapkan, karena salah satu kompetensi yang dimiliki adalah kompetensi pedagogik.

Menurut Mulyasa (2012 : 75) kompetensi pedagogik guru merupakan kemampuan mengelola pembelajaran peserta didik. Dengan memiliki kompetensi ini, guru menguasai berbagai teori belajar dan pembelajaran sehingga mampu meyusun dan mengaplikasikasn sebuah rancangan kegiatan pembelajaran yang mendidik dan bermakna bagi siswa. Dengan demikian, sebagai seorang guru harus mampu guru mengiplementasikan model-model pembelajaran sesuai dengan teori dari model pembelajaran tersebut agar hasil yang diharapkan akan terwujud.

\section{KESIMPULAN}

Berdasarkan hasil analisis data dan pengujian hipotesis, maka dapat disimpulkan bahwa terdapat pengaruh motivasi belajar terhadap hasil belajar siswa dalam penerapan model pembelajaran ARIAS (Assurance, Relevance, Interest, Assessment, dan Satisfaction). Berdasarkan hasil penelitian, disarankan guru selalu memotivasi siswa diluar maupun didalam kegiatan pembelajaran. Misalnya, dengan memberi pujian atau hadiah. Selanjutnya dengan penerapan model pembelajaran ARIAS siswa termotivasi untuk belajar matematika sehingga hasil belajarnya yang cukup baik sehingga penilitian lanjutan 
mengenai kemampuan matematis lainnya dengan penerapan model pembelajaran ARIAS dapat dilakukan.

\section{REFERENSI}

Adam, S. (2002). Using Learning Outcomes: A consideration of the nature, role, application and implications for European education of employing 'learning outcomes' at the local, national and international levels. Edinburgh, Scotland: Heriot-Watt University.

Fatchurrohman, G. (2011). Pengaruh Motivasi Berprestasi terhadap Kesiapan Belajar, Pelaksanaan Prakerin dan Pencampaian Kompetensi Mata Pelajaran Produktif. Dalam jurnal UPI . [Online], Edisi khusus (2), 10 halaman. Tersedia: jurnal. Upi.edu. [28 januari 2017].

Hamdhu, G dan Agustiana, L. (2011). Pengaruh Motivasi Belajar Siswa terhadap Prestasi Belajar IPA. Dalam jurnal UPI .[Online], Vol 12 (1), 7 halaman. Tersedia: jurnal.Upi.edu. [28 januari 2017].

Lestari, A., Nursalam, dan Mardhiah. (2017). Pengaruh Model Pembelajaran ARIAS terhadap Hasil Belajar Matematika Peserta Didik kelas VII SMPN 1 Sungguminasa Kab. Gowa. MaPan : Jurnal Matematika dan Pembelajaran Vol. 5 No.1.[Online]. Tersedia journal.uin-alauddin.ac.id. [28 januari 2017].

Maizon, H. (2010). Pembelajaran kuantum untuk meningkatkan kemampuan pemahaman matematika dan motivasi belajar siswa.tesis UPI: tidak diterbitkan.

Mulyasa. (2012). Standar Kompetensi dan Sertifikasi Guru. Bandung: Rosdakarya.

Nasih, A.,M. dan Kholidah, L.N. (2009). Metode dan Teknik Pembelajaran Pendidikan Agama Islam. Bandung: PT Refika Aditama.

Pebrinovita, W. (2013). Pengaruh Kompetensi Profesional dan Pedagogik Guru Ekonomi terhadap Motivasi Belajar Siswa SMA. [Online]. Tersedia: http://repository.unri.ac.id. [28 januari 2017].

Rahman,M. dan Amir, S. (2014). Model Pembelajaran ARIAS Terintegratif dalam Teori dan Praktik untuk Menunjang Penerapan kurikulum 2013. Jakarta: Prestasi Pustaka Raya

Ruseffendi, E.T. (2006). Pengantar kepada Membantu Guru Mengembangkan Kompetensinva dalam Pengajaran Matematika untuk Meningkatkan CBSA. Bandung: Tarsito.

Siregar, E. dan Nara, H. (2010). Teori Belajar dan Pembelajaran. Bogor: Ghalia Indonesia.

Suprijono. (2010). Cooperative Learning: Teori dan Aplikasi PAIKEM. Yogyakarta: Pustaka Pelajar.

Syah, M. (2007). Psikologi Pendidikan. Jakarta: Rajawali Grafindo Persada.

Sudjana, N. (2009). Penilaian Hasil Proses Belajar Mengajar. Bandung: PT Remaja Rosdakarya.

Uno, H. B. (2006). Teori Motivasi dan Pengukurannya Analisis Di Bidang Pendidikan. Jakarta: Bumi Aksara. 